\title{
A Smart Information Storage Equipment with High-Capacity and Energy Level-Indicating Functionality
}

\author{
Jinxiong Zhao, Hui Yuan, Lina Gao, Bo Gong, Zhiru Li, Fan Yang \\ Xiaogin Zhu, Yong Zhi \\ Grid Technology Center, State Grid Gansu Electric Power Research Institute, Lanzhou 730070, \\ China.
}

\begin{abstract}
The tendency that the neonatal smart storage devices are integrated with energy storage and electrochromism functions have captured enormous attentions, showing potential applications in energy conservation, emission reduction and environmental protection. Here, we demonstrate a new approach to improve the capacity $(170 \mathrm{mAhg}-1)$, which is almost three times larger than that the recently reported approach simply through by enlarging voltage range (0.3-2.5 V). The improved capacity may come from complicated structure and valence state variation of Prussian blue, which facilitate the two pair redox reactions. Metal aluminum was used to reduce Prussian blue (PB) to Prussian white (PW) then to Berlin green (BG) in potassium chloride electrolyte and vice versa. That is, there are two charging/discharging processes in our battery (Smart Information Storage Equipment) providing a higher capacity than that provided by only one. Additionally, the device we designed would provide a convenient user-device interface based on a three-colored humanreadable output.
\end{abstract}

Keywords: Smart Information Storage Equipment, Electrochromic Information Storage Equipment, High-Capacity.

\section{Introduction}

Batteries, parts of the most widespread energy storage devices have been intensively investigated, playing an important role in modern human life [1-3]. The application of batteries are also positive solutions for energy shortage and global warming that the world is currently facing to promote the environmental sustainability. Previous work is committed to solve the conventional problems of batteries, such as low capacity, unsatisfied cycle life span, and so on [4-7]. While current efforts have been made to the smart applications required along with an improved demand of the flexibe, fiber devices and smart applications with convenient user-device interface based on a friendly humanreadable output [8-10]. In our previous work, an smart energy storage approach was proposed, in which a pattern of "SINANO" indicating the energy storage at different levels through the colors change of electrodes driven by the external bias was demonstrated [8]. Recently, Sun's group has reported a typical smart device of potential application in the future, who used electrochromic Prussian blue as the electrode material with the operating voltage for of $1.26 \mathrm{~V}$ and the optimal discharge capacity of $72.2 \mathrm{mAhg}^{-1}$ [4]. Obviously, they provided a bi-functional device: self-powered electrochromic window and self-rechargeable transparent battery. Additionally, the energy storage state can be directly observed by the color change of the electrode. The concept of such equipment is extremely innovative and will possibly open the door for the development of novel multifunctionalized battery. The newly exploited field of smart batteries, however, still leaves a crucial problem to be addressed, that is the specific capacity $\left(72.2 \mathrm{mAhg}^{-1}\right)$ of such electrochromic battery delivers is still too low to meet the requirements of practical application.

\section{Methodology}

It is well known that electrochromic materials, previously explored to exhibit battery characteristics, are able to store and release ions at switching biases. PB is an impotant clan of traditional electrochromic materials and pioneered by Neff et al [11-15]. There are two transformation modes of valence state, among which PB can act either as an oxidant to accept one electron transforming into reduced $\mathrm{PW}$ or as a reductant to lose one electron turning into $\mathrm{BG}$ at different 
potential intervals. Therefore, we select $\mathrm{PB}$ and aluminum (Al) as anode and cathode materials for the cell fabrication respectively. The measured open circuit voltage of the cell is $1.2 \mathrm{~V}$ with 1 Mpotassium chloride $(\mathrm{KCl})$ electrolyte. In order to seek the appropriate battery voltage range, applied biases are first set between -0.4 and $1.45 \mathrm{~V}$ to focus on the redox reactions using a threeelectrode system with $\mathrm{PB}, \mathrm{Al}$ and $\mathrm{Ag} / \mathrm{AgCl}$ as the working, counter and reference electrodes, respectively (Figure $\mathrm{S} 1$ ). Then, with regard to the two-electrode $\mathrm{Al} / \mathrm{PB}$ cell, the cyclic voltammetry configuration is monitored from $0.3 \mathrm{~V}$ to $2.6 \mathrm{~V}$, which is calculated from the potential difference of $\mathrm{Al}$ versus $\mathrm{Ag} / \mathrm{AgCl}$ (about $-0.9 \mathrm{~V}$ ) by electrochemical workstation (Figure 1a).
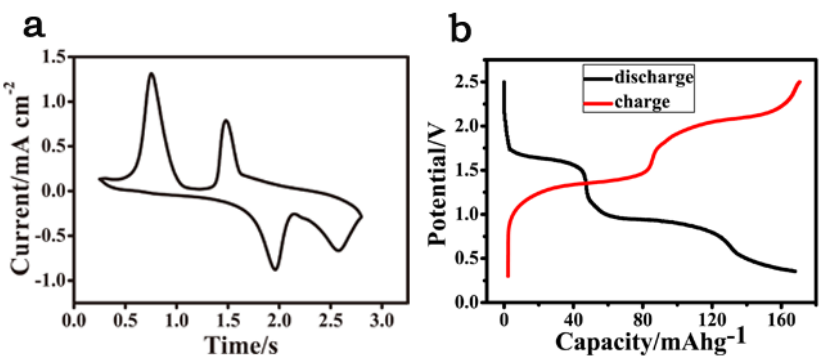

Fig. 1 Electrochemical characterization of Al-PB battery: (a) The cyclic voltammetry curve at the scan rate of $5 \mathrm{mV}$ s-1 employing two-electrode system; (b) The lines of galvanostatic charge and discharge capacity measured at a current density of $1400 \mathrm{mAg}-1$, the red and black solid lines represented the charge and discharge process, respectively.

There are two pair of redox peaks appearing with electrode material at the potentials $(\mathrm{V})$ of $(0.75$, $1.9 \mathrm{~V})$ and $(1.48,2.5 \mathrm{~V})$, respectively, the first pair of peaks can be attributed to the redox reactions between $\mathrm{PB}$ and $\mathrm{PW}$ along with $\mathrm{K}+$ and one compensated electron inserted or extracted into/from the lattice of electrode materials. While the reason for another pair of peaks is the reversible transformation between PW and BG with the insertion or extraction of $\mathrm{K}+$ together with another one compensating electron. In line with the $\mathrm{CV}$ result, two platforms can be observed in the galvano-static charge and discharge processes as shown in the Figure 1b. For charge curve, the first platform is consistent with the results previous reported by Sun's group, which occurs at $1.25 \mathrm{~V}$ in accordance with reaction (1). And the second one appears at $1.75 \mathrm{~V}$ corresponding to the reaction (2). For discharge line, the first platform occurs at $1.75 \mathrm{~V}$ and the second one appears at $1 \mathrm{~V}$, corresponding to the reaction (3) and (4), respectively. The discharge and charge capacity are calculated to be 168mAhg-1 and 170.33mAhg-1, respectively, which are extremely higher than that reported by the Sun's group. The discharge capacity is very close to the charge capacity, indicating a perfect reversibility in the discharging and charging of our battery.

$$
\begin{array}{r}
\mathrm{K}_{2} \mathrm{Fe}^{\mathrm{II}}\left[\mathrm{Fe}^{\mathrm{II}}(\mathrm{CN})_{6}\right](\mathrm{PW})-\mathrm{K}^{+}-\mathrm{e}^{-}=\mathrm{KFe}^{\mathrm{III}}\left[\mathrm{Fe}^{\mathrm{II}}(\mathrm{CN})_{6}\right](\mathrm{PB}) \\
\mathrm{KFe}^{\mathrm{III}}\left[\mathrm{Fe}^{\mathrm{II}}(\mathrm{CN})_{6}\right](\mathrm{PB})-\mathrm{K}^{+}-\mathrm{e}^{-}=\mathrm{Fe}^{\mathrm{III}}\left[\mathrm{Fe}^{\mathrm{III}}(\mathrm{CN})_{6}\right](\mathrm{BG}) \\
\mathrm{Fe}^{\mathrm{III}}\left[\mathrm{Fe}^{\mathrm{III}}(\mathrm{CN})_{6}\right](\mathrm{BG})+\mathrm{K}^{+}+\mathrm{e}^{-}=\mathrm{KFe}^{\mathrm{III}}\left[\mathrm{Fe}^{\mathrm{II}}(\mathrm{CN})_{6}\right](\mathrm{PB}) \\
\mathrm{KFe}^{\mathrm{III}}\left[\mathrm{Fe}^{\mathrm{II}}(\mathrm{CN})_{6}\right](\mathrm{PB})+\mathrm{K}^{+}+\mathrm{e}^{-}=\mathrm{K}_{2} \mathrm{Fe}^{\mathrm{II}}\left[\mathrm{Fe}^{\mathrm{II}}(\mathrm{CN})_{6}\right](\mathrm{PW})
\end{array}
$$

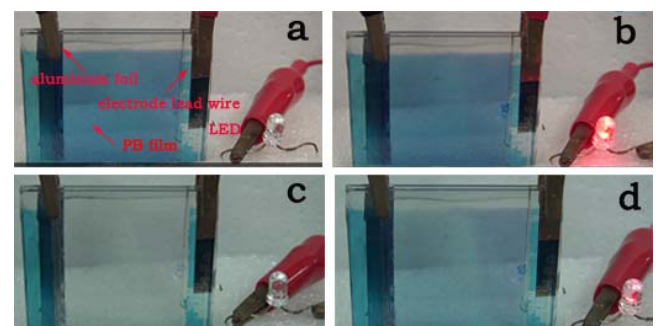

Fig.2 Visual photos of the electrochemical Al-PB battery: (a) The initial state is blue in color, implying a full power state with disconnection of the both electrodes; (b) The LED is lightened at the brightest when one connects the two electrodes together; (c) The Al-PB battery remains a transparent state and the LED cannot be lightened indicating that the electric power storage of the 
device has been exhausted; (d) The Al-PB battery spontaneously recovers to thirsty blue and the

LED can be lightened again after $24 \mathrm{~h}$ in air, indicating that the device is self-charged but not completely.

Another meaningful function of the as-prepared cell is the human-readable color output that is to say we can recognize the energy storage states through the different color states. We can catch sight of the initial state of the electrochromic battery in Figure $2 \mathrm{a}$. And the chromic states of Al-PB battery can also be monitored in the whole visible range $(400-800 \mathrm{~nm})$ under differently self-charged condition by in situ UV-vis spectroscopy as shown in Figure $3 b$. The transmittance of the device is kept at $10 \%$ as the self-charged time increased from 5 to $40 \mathrm{~min}$ in air. The initial state of Al-PB battery under full charged condition typically manifests much lower light transmittance than that of the exhausted Al-PB battery as shown in Figure 3a, and the maximal optical modulation (60\%) is definitely high enough to be observed even after the penetration from two FTO (SnO2: F) glasses and electrolyte. The original battery exhibits a blue color, which means a situation of full power. At the meantime, the light emitting diode (LED) is lightened at its brightest when the positive and negative electrodes were connected together by the metal wires to make a circuit (Figure 2b). As the discharged battery showing a transparent appearance, the LED cannot be lighted up (Figure 2c), demonstrating that the energy of the battery is used up. As shown in Figure 2d, by simply disconnecting the $\mathrm{Al}$ and PB electrodes, the device can be self-charged after exposure to air for $24 \mathrm{~h}$ due to oxidization of PW by $\mathrm{O}_{2}$ in the air. At this time, the LED is lightened again but with dim brightness which signifies the materials is not activated completely.
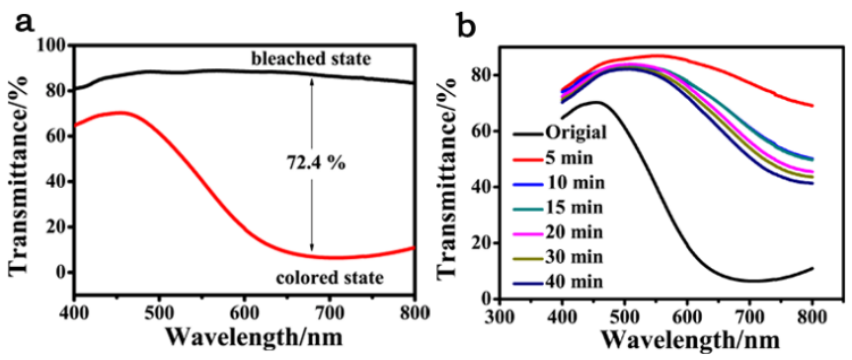

Fig.3 The characterization of the transmittance of the Al-PB battery transmittance: (a) The transmittance of bleached and colored state is monitored by in situ UV-vis spectroscopy. The maximum optical modulation is $72.4 \%$ at $670 \mathrm{~nm}$; (b) The transmittance spectra of our battery is measured at various recovery times at $0 \mathrm{~min}, 5 \mathrm{~min}, 10 \mathrm{~min}, 15 \mathrm{~min}, 20 \mathrm{~min}, 30 \mathrm{~min}$ and $40 \mathrm{minby}$ in situ UV-vis spectroscopy.

It deserves to be mentioned that the as-prepared $\mathrm{Al} / \mathrm{PB}$ battery can also serve as electrochromic windows that can operates with no external driving force. The window can keep in blue and protect the house from hurting by the strong ultraviolet ray, when one keeps the Al and PB electrodes disconnecting, while the window can be changed into transparent to improve the visible transparency at any time by simply connecting the $\mathrm{Al}$ and $\mathrm{PB}$ electrodes. The bleaching and coloring processes correspond to the charging and discharging processes, respectively. For our battery, there are two approaches that could be chosen to charge the exhausted battery: (1) charged by the external bias, such as electrochemical workstation and mobile power; (2) charged by oxygen in the open. If external bias is used to drive our battery, it will tremendously accelerate the coloration rate by quick insertion and removal of the ions, the reversible change between high and low transmittance means a good reversibility, as shown in Figure $\mathrm{S}_{2}$. The initial discharge capacity of our Al-PB electrochromic battery accurately monitored at $-2 \mathrm{~V}$ for $60 \mathrm{~s}$ is $200 \mathrm{mAhg}-1$ by the electrochemical workstation as shown in Figure 4a.The charge capacity of the recovered Al-PB electrochromic battery recharged at $2.5 \mathrm{~V}$ for $60 \mathrm{~s}$ is $200 \mathrm{mAhg}-1$ and the electrochromic battery after spontaneous recovery via exposure to air for $24 \mathrm{~h}$ is $80 \mathrm{mAhg}-1$. The first discharge capacity is approximately equal to $100 \%$ of the first dischargeable amount of the battery, compared with the only $40 \%$ by recovery storage in air in Figure $4 \mathrm{~b}$. At last, the Al-PB electrochromic battery is experienced 20 cycles to evaluate its endurance 
(Figure $4 \mathrm{~b}$ ). The charging and discharging capacity at constant voltage are almost equal to the capacity of galvano static charging and discharging, indicating a good reversibility again for the Al-PB electrochromic battery.
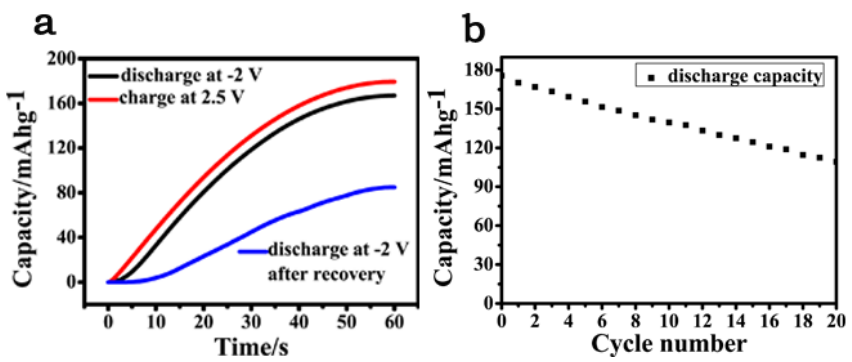

Fig.4 Specific capacities of the electrochemical Al-PB battery. (a) The battery is charged at $2.5 \mathrm{~V}$; (b) The battery discharges at $-2 \mathrm{~V}$; (c) The battery is charged for $24 \mathrm{~h}$ in air.

\section{Summary}

In summary, we have successfully manufactured an electrochromic battery that possesses very high capacity and exhibits energy storage indication in color at different charged/discharged states. We employ the multi-valence state redox reaction of $\mathrm{PB}$ as electrode material to enlarge the voltage gap and largely improve the capacity of the electrochromic battery of $\mathrm{Al} / \mathrm{PB}$. The devices we have fabricated deliver an amazingly high discharge capacity of $429 \mathrm{mAhg}^{-1}$, which is approximately three times higher than the best capacity reported in previous literatures for the electrochromic batteries. Our advanced results may come from the following aspects: the intricate combination of structure and multi-valence state change of PB.

\section{References}

[1]. J. Chmiola, C. Largeot, P.-L. Taberna, P. Simon, Y. Gogotsi. Monolithic carbide-derivd carbon films for micro-supercapactiors. Science 328, 2010, pp.480-483.

[2]. T. Janoschka, N. Martin, U. Martin, C. Friebe, S. Morgenstern, H. Hiller, M. D. Harger, U.S. Schubert. An aqueous, polymer-based redox-flow battery using non-corrosive, safe, and low-cost materials. Nature 527, 2015, pp. 78-81.

[3]. K.Wang, K.Jiang, B. Chung, T. Ouchi, P.J. Burke, D.A.Boysen, D.J. Bradwell, H. Kim, U. Muecke, D.R. Sadoway. Lithium-antimony-lead liquid metal battery for grid-level energy storage. Nature, 2014, pp.348-350.

[4]. J. Wang, L. Zhang, L. Yu, Z. Jiao, H. Xie, X.W. Lou, X.W. Sun. A bi-functional device for selfpowered electrochromic window and self-rechargeable transparent battery applications. Nat. Commum.5, 2014, 4921.

[5]. Z. Weng, F. Li, D.W. Wang, L. Wen, H.M. Cheng. Controlesd electrochemical charge injection to maximize the energy density of supercapacitors. Angew. Chem. lnt. Ed. 52, 2013, pp.37223725 .

[6]. G. Zhou, S. Pei, L. Li, D. W. Wang, S. Wang, K. Huang, L. C. Yin, F. Li, H. M. Cheng. A grapheme-pure-sulfur sandwich structure for ultrafast, long-life lithium-sulfur batteries. Adv.Mater.26, 2014, pp.625-631.

[7]. C.Hu, G. Zheng, F. Zhao, H. Shao, Z. Zhang, N. Chen, L. Jiang, L. Qu. A powerful approach to functional graphene hybrids for high performance energy-related applications. Energy Environ. Sci.7, 2014, pp.3699-3708. 
[8]. Y. Tian, S.Cong, W. Su, H. Chen, Q. Li, F. Geng, Z. Zhao, Synergy of W18O49 and polyaniline for smart supercapacitor electrode integrated with energy level indicating functionality. Nano Lett.14, 2014, pp.2150-2156.

[9]. Y.Zhang, L.Wang, Z.Guo, Y.Xu, Y.Wang, H.*Peng. "High-performance lithium-air battery with a coaxial-fiber architecture” , Angew. Chem. Int. Ed. 2016, 55, pp.4487-4491.

[10]. L.Liu, J.Pan, P.Chen, J.Zhang, X.Yu, X.*Ding, B.Wang, X.Sun, H.*Peng. “A triboelectric textile templated by a three-dimensionally penetrated fabric”, J. Mater. Chem. A 2016, 4, pp.6077-6083.

[11]. V.D. Neff. Electrochemical oxidation and reduction of thin-films of Prussianblue. J. Electrochem. Soc. 125, 1978, pp.886 - 887.

[12]. D.Ellis, M.Eckhoff \& V.D. Neff. Electrochromism in the mixed-valencehexacyanides. 1. Voltammetric and spectral studies of the oxidationand reduction of thin films of Prussian blue. J. Phys. Chem. 85, 1981, pp.1225 - 1231.

[13]. K.Itaya, H.Akahoshi \& S.Toshima. Prussian-blue-modified electrodes-anapplication for a stable electrochromic display device. J. Appl. Phys. 53, 1982, pp.804-805.

[14]. K.Itaya, H.Akahoshi \& S. Toshima. Electrochemistry of Prussian bluemodified electrodesan electrochemical preparation method. J. Electrochem. Soc. 129, 1982. pp. 1498-1500.

[15]. K. Itaya, T. Ataka \& S. Toshima. Spectroelectrochemistry and electrochemicalpreparation method of Prussian blue modified electrodes. J. Am. Chem. Soc.104, 1982, pp.4767- 4772. 